BRomerschenkel, I. e FIgueiró, G.M. Pitiose em equinos. PUBVet, Londrina, V. 8, N. 22, Ed. 271, Art. 1807, Novembro, 2014.

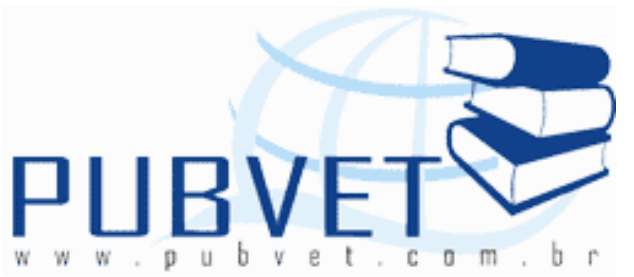

PUBVET, Publicações em Medicina Veterinária e Zootecnia.

\title{
Pitiose em equinos
}

${ }^{1}$ Pós graduanda em Ciências Veterinárias, Universidade Federal do Espírito Santo - UFES

${ }^{2}$ Docente na área de Clinica e Reprodução de Equinos, Centro Universitário do Espirito Santo - UNESC/Colatina - ES e Escola São Francisco de Assis ESFA/Santa Teresa - ES

\section{Resumo}

A pitiose é uma doença piogranulomatosa, causada pelo oomiceto Pythiuminsidiosum. É de ocorrência mundial, sendo mais frequente em regiões de clima temperado, tropical e subtropical. Já foi relatada em vários estados brasileiros, sendo o Pantanal considerado o local com maior frequência de pitiose no mundo. A espécie equina é mais atingida pela doença, havendo vários relatos da doença no Brasil. Seu diagnóstico pode ser realizado pelo aspecto clínico, histopatológico, cultura e isolamento do P. insidiosum, imunohitoquímica, ELISA e por meio métodos moleculares. Os métodos terapêuticos mais utilizados para o tratamento da pitiose são: cirurgia, químico, imunoterapia e a combinação destes, sendo a imunoterapia o mais promissor dos tratamentos.

Palavras-chave: Equino, ficomicose, tratamento. 
BRomerschenkel, I. e FIgueiró, G.M. Pitiose em equinos. PUBVet, Londrina, V. 8, N. 22, Ed. 271, Art. 1807, Novembro, 2014.

\title{
Pythiosis in equine
}

\begin{abstract}
Pythiosis pyogranulomatous is a disease caused by the oomycete Pythiuminsidiosum. Is occurring worldwide, being more common in temperate regions, tropical and subtropical regions.It has been reported in several Brazilian states, the Pantanal is considered the site with the highest frequency of pythiosis in the world. The equine species is most affected by the disease, with several reports of the disease in Brazil. Its diagnosis can be made by clinical appearance, histopathology, culture and isolation of $P$. insidiosum hitoquímica immunohistochemical, ELISA and bymolecular methods. The therapeutic methods used to treat arrhythmias of pythiosis are: surgical, chemical, and the combination of immunotherapy, immunotherapy is the most promising treatments
\end{abstract}

Keywords: equine, phycomycosis, treatment.

\section{INTRODUÇÃO}

A pitiose é uma zicomicose, que constitui um grupo complexo de doenças piogranulomatosas (BIAVA et al., 2007). É uma doença infecciosa, de localização cutâneo-subcutânea e eventualmente sistêmica (PEREIRA e MEIRELES 2007). É considerada uma doença emergente (VANITTANAKOM et al., 2004), sendo a espécie equina a mais atingida (SANTURIO et al, 2001).

As lesões são granulomatosas, ulceradas e serosanguinolentas, apresentando nódulos necróticos (LEAL et al., 2001). Vários tratamentos vêm sendo usados em equinos ao longo dos anos, sendo a imunoterapia uma das alternativas de controle da doença que tem apresentado os resultados mais promissores (MONTEIRO, 1999). 
BROMERSCHENKeL, I. e FIGUeIRÓ, G.M. Pitiose em equinos. PUBVet, Londrina, V. 8, N. 22, Ed. 271, Art. 1807, Novembro, 2014.

\section{DESENVOLVIMENTO}

\section{Etiologia}

O agente etiológico da pitiose é o Pythiuminsidiosum, pertencente ao reino Stramenopila, filo Oomycota, classe Oomycetes, ordem Peronosporales e família Pythiaceae. Esse organismo encontra-se em ambientes aquáticos, em especial em regiões alagadas, com temperatura superior a $25^{\circ} \mathrm{C}$ (LEAL et al., 2001).

Através de amostras proveniente de humanos e animais, de várias regiões do mundo, foi demostrado que $P$. insidiosum se divide em três filogenéticos, clado I, II e III. O clado I foi isolado apenas no hemisfério oeste, e o II e III, isolado no resto do mundo (SCHURKO et al., 2003; SUPABANDHU et al., 2008; CHAIPRASERT et al., 2009). Existe a hipótese de que a variação genética do $P$. insidiosum estivesse ligada as diferenças clínicas manifestadas entre as espécies, mas ainda não se estabeleceu associação entre a especificidade entre as variações e as regiões geográficas e hospedeiros (CHAIPRASERT et al., 2009).

\section{Epidemiologia (prevalência)}

A pitiose é uma doença cosmopolita, sendo mais frenquente em regiões de clima temperado, tropical e subtropical. O primeiro caso de pitiose equina no Brasil foi relatado no Rio Grande do Sul (Santos e Londero 1974, apud SANTURIO et al., 2006). Depois já foi relatada em diversos estados brasileiros tais como Paraíba (TABOSA et al., 2004), Rio Grande do Sul ( SALLIS, PEREIRA e RAFFI, 2003), Paraná (LUVIZARI, LEHMKUHL e SANTOS, 2002), Sergipe (BANDEIRA et al., 2009), Mato Grosso, Rio de Janeiro, (PEREIRA e MEIRELES 2007). O pantanal brasileiro é considerado o local com maior frequência de pitiose no mundo (SANTURIO et al, 2001). 
BRomerschenkel, I. e FIgueiró, G.M. Pitiose em equinos. PUBVet, Londrina, V. 8, N. 22, Ed. 271, Art. 1807, Novembro, 2014.

Já foi descrita em equinos (FIORETTI et al., 2002; REIS JÚNIOR e NOGUEIRA, 2002; LUVIZARI; LEHMKUHL e SANTOS, 2002; HEADLEY e ARRUDA JUNIOR, 2004; FREY JÚNIOR, et al., 2007) bovinos (GABRIEL et al., 2008; GRECCO et al., 2009), ovinos (TABOSA et al., 2004), humanos (BOSCO et al., 2005; MARQUES et al., 2006; VICARIVENTO et al., 2008), e nos animais silvestres: urso-de-óculos (GROOTERS, 2003), onça pintada (CAMUS, GROOTERS e AQUILAR, 2004), dromedário (WELLEHAN, et al., 2004), tigre de bengala (BUERGELT, POWE e WHITE, 2006) e ave migratória (PESAVENTO et al, 2008).

Não há predisposição de raça, idade e sexo (SANTURIO et al., 2001). A fonte de transmissão são os zoósporos ambientais, e Mendoza et al. (2005), publicaram que não haviam relatos sobre a transmissão direta entre animais e animais e o homem. Em 2010 Dória et al. (2010), relataram um caso de transmissão direta de pitiose em equinos. No caso o animal apresentava uma ferida de pitiose no membro e uma ferida lacerativa na boca, e adquiriu uma nova infecção de pitiose ao coçar a ferida de pitiose do membro com a boca, havendo então a transmissão direta do oomiceto da ferida infectada do membro para a ferida lacerada da boca.

A maioria dos casos de pitiosesão observados durante ou após a estação chuvosa, e acredita-se que existe um período de incubação de várias semanas antes da manifestação clínica da doença (SANTURIO et al, 2001).

\section{Patogenia}

O P. insidiosum é encontrado em água parada, infectando plantas aquáticas. Reproduz-se de forma sexuada, dando origem aos zoosporângios (MILLER, 1983; MENDOZA HERNANDEZ e AJELLO, 1993; BIAVA et al., 2007). Os zoósporos livres na água tem um forte tropismo por pêlos e por tecidos animais e vegetais, onde se encistam e secretam um material amorfo que os 
Bromerschenkel, I. e figueiró, G.M. Pitiose em equinos. PUBVet, Londrina, V. 8, N. 22, Ed. 271, Art. 1807, Novembro, 2014.

permite ficar aderidos a superfície do seu hospedeiro (MENDOZA, HERNANDEZ e AJELLO, 1993).

A patogenia ainda é discutível, entretanto a maioria dos autores acredita que o organismo precise de uma porta de entrada para infectar o animal. A porta de entrada estabelece uma solução de continuidade, onde o microrganismo penetra e coloniza o tecido do animal, formando um piogranulomaeosinofílico, onde o mesmo fica envolto por uma massa necrótica amorfa chamanda "kunker" (PEREIRA e MEIRELES 2007).

Os kunkerssão massas irregulares, firmes, necróticas, amarelas e granulares com aspecto arenoso (MENDOZA e ALFARO, 1986; LEAL et al., 2001). Histologicamente são formados de fragmentos de hifas circundadas e embebidas por numerosos eosinófilos, desgranulados e intactos, detritos eosinofílicosabundandes (BROWN e ROBERTS, 1988 apud MARTINS 2010), e com proliferação de tecido de granulação e tecido conjuntivo. Em casos crônicos também é possível encontrar células gigantes (MENDOZA e ALFARO, 1986).

A reação eosinofílica impede a ação das células de defesa do hospedeiro, pois forma uma capa de proteção sobre os filamentos do microrganismo, sendo assim, o hospedeiro não é capaz de formar uma estimulação antigênica. A lesão subcutânea evolui rapidamente em poucas semanas, tornando-se uma massa esbranquiçada que fistula e drena continuamente um exsudato serossanguinolento. A evolução rápida da doença deixa o animal caquético e inapto para o trabalho, podendo levar a morte (PEREIRA e MEIRELES 2007).

\section{Manifestação clínica}

Geralmente as lesões causadas pelo $P$. insidioum estão localizadas nas regiões do corpo onde o animal tem contado com a água, como a extremidade dos membros, região ventral do abdômen e peito, face, narinas e cavidade oral 
BRomerschenkel, I. e FIgueiró, G.M. Pitiose em equinos. PUBVet, Londrina, V. 8, N. 22, Ed. 271, Art. 1807, Novembro, 2014.

(MENDOZA e ALFARO, 1986; MEIRELES et al., 1993; CHAFFIN, SCHUMACHER e MCMULLAN, 1995; LEAL, et al., 2001; SALLIS, PEREIRA e RAFFI, 2003; TABOSA et al., 2004; D' UTRA VAZ et al., 2009).

Os principais achados clínicos são: prurido, edema, dor, apatia, inapetência, emagrecimento progressivo, hipoproteinemia e piodermites secundárias (MEIRELES et al., 1993; CHAFFIN, SCHUMACHER e McMULLAN, 1995; LEAL et al., 2001). O prurido intenso e a dor, levam o animal a auto-mutilação, na tentativa de aliviar o desconforto. A claudicação é frequente nos animais com lesões nos membros (MENDOZA e ALFARO, 1986; LEAL et al., 2001).

O emagrecimento progressivo está associado à liberação de fatores de necrose tumoral, que são liberados em infecções por bactérias Gram-negativas, que podem estar presentes em infecções secundárias nas feridas, observadas em alguns casos de pitiose (LEAL et al, 2001).

Pode manifestar em lesões cutâneas únicas ou múltiplas (CHAFFIN, SCHUMACHER e HOOPER, 1992; CHAFFIN, SCHUMACHER e MCMULLAN, 1995), lesões intestinais (PURCELL et al., 1994; DALTO et al., 2007), lesões ósseas (ALFARO e MENDOZA, 1990, apud MARTINS 2010) ocorrendo também casos de metástase via linfática (MURRAY et al., 1978 apud MARTINS, 2010).

As lesões cutâneas são as mais frequentes em equinos. Inicialmente são pequenas, com aspecto circular, podendo aumentar de maneira ulcerativa (KNOTTEMBELT e PASCOE, 1998; LUVIZARI, LEHMKUHL e SANTOS, 2002). Estas lesões são compostas de massas granulomatosas amplas e grosseiramente redondas, na maioria das vezes ulcerada, com fístulas que drenam líquido serossanguinolento. Dentro dessas fístulas é possível observar kunkers (MENDOZA e ALFARO, 1986; LEAL et al., 2001).

A segunda forma mais frequente de pitiose em equinos é a intestinal. Os casos já relatados cursaram com episódios de cólica, causados pela presença de massas, que reduziam ou obstruíam o lúmen intestinal (PURCELL et al., 1994). 
BRomerschenkel, I. e FIgueiró, G.M. Pitiose em equinos. PUBVet, Londrina, V. 8, N. 22, Ed. 271, Art. 1807, Novembro, 2014.

\section{Diagnóstico}

O diagnóstico da pitiose pode ser realizado pelo aspecto clínico, histopatológico, cultura e isolamento do $P$. insidiosum, imuno-histoquímica, ensaio imunoenzimático ELISA, e os métodos moleculares (MENDOZA; KAUFMA e STANDARD, 1986; DÓRIA, 2009).

O diagnóstico presuntivo pode ser feito, levando-se em conta os sinais clínicos, epidemiologia, e os aspectos macro e microscópicos das lesões.

O exame histopatológico é auxiliar no diagnóstico e necessita de outras provas para a confirmação (BROWN e ROBERTS, 1988 apud MARTINS 2010). É realizado com a fixação da amostra em formol a $10 \%$, processadas rotineiramente para exame histopatológico e coradas pela hematoxilinaeosina e coloração de Prata Metenamina de Grocott (PEDROSO et al., 2009). As hifas do $P$. insidiosum ficam impregnadas por essa colocação, tornando mais fácil a sua identificação (PEREIRA e MEIRELES 2007).

O diagnóstico da pitiose baseado em cultura raramente é definitivo, porque a produção e identificação de estruturas reprodutivas são difíceis (GROOTERS e $\mathrm{GEE}$, 2002). As infecções secundárias, que são observadas frequentemente nas feridas representam uma dificuldade adicional para o isolamento do agente (LEAL et al., 2001). O isolamento pode ser feito através de kunkers, que antes de serem semeados em Agar Sabouraud Dextrose devem ser lavados em soluções contendo antibióticos (BANDEIRA et al., 2009).

O teste imuno-histoquímico é altamente específico (REIS JUNIOR e NOGUEIRA, 2002) É uma ferramenta importante como método de diagnóstico nos casos em que se tem suspeita de pitiose em casos nos quais fragmentos do tecido lesionado estão fixados em formalina e quando o material submetido não pode mais ser utilizado para o cultivo (PEDROSO et al., 2009).

O ensaio imunoenzimático indireto ELISA tem sido empregado para o diagnóstico precoce de pitiose em humanos e animais possibilitando a detecção 
BROMERSCHENKeL, I. e FIGUeIRÓ, G.M. Pitiose em equinos. PUBVet, Londrina, V. 8, N. 22, Ed. 271, Art. 1807, Novembro, 2014.

de infecções ainda subclínicas (MENDOZA et al., 1997). É realizado através de uma amostra de soro, sendo que sua sensibilidade chega a 97,72\% e especificidade a 90,27\% para o diagnóstico da pitiose em equinos (SANTURIO et al., 2006)

Métodos de diagnóstico envolvendo biologia molecular como Western Blotting e Reação em cadeia da polimerase (PCR) tem se mostrado eficientes para diagnóstico da pitiose (VANITTANAKOM et al., 2004). Em 2002, Grooters e Geedesenvolvevam, um ensaio com PCR para a identificação de $P$. insidiosum, e os resultados sugerem que o PCR é uma ferramenta de alta especificidade e útil para a identificação do $P$. insidiosum.

\section{Diagnóstico diferencial}

O diagnóstico diferencial para pitiose inclui: habronemose, sarcóide, tecido de granulação exuberante e granulomas fúngicos e bacterianos (CHAFFIN; SCHUMACHER E HOOPER, 1992).

\section{Tratamentos}

O sucesso do tratamento depende do tempo de instalação, local da lesão, tamanho, idade e estado nutricional do animal, sendo que frequentemente é relatado insucesso ou recidiva (MENDOZA et al., 1997)

O prognóstico depende do comprometimento das estruturas vizinhas à ferida, como articulações, fáscias, tendões e tecido ósseo. Como a evolução é rápida, devido à automutilação, com perda significativa de sangue levando ao emagrecimento profuso e debilidade orgânica o animal pode vir a óbito (LEAL et al., 2001; BIAVA et al., 2007; MACIEL et al., 2008). 
Bromerschenkel, I. e figueiró, G.M. Pitiose em equinos. PUBVet, Londrina, V. 8, N. 22, Ed. 271, Art. 1807, Novembro, 2014.

Os métodos terapêuticos mais utilizados para o tratamento da pitiose são: cirurgia, quimioterápico e imunoterapia (SANTURIO et al, 2001). Já foram relatados também utilização de sulfato de cobre (MEIRELES et al., 2003), laser (SEDRISH, et al., 1997), dimetilsulfóxido (DMSO) e suas associações (DIAS et al., 2011).

A cirurgia consiste em remoção de toda a lesão (FOIL et al., 1984 apud MARTINS 2010 ), mas em alguns casos, quando a lesão é localizada na extremidade dos membros, a excisão cirúrgica é inviável (MILLER, 1981). A excisão deve ser realizada com uma margem de segurança, contemplando as bordas da pele que aparentemente se encontram íntegras. Por ser uma região muito vascularizada, geralmente ocorrem hemorragias, que podem ser contidas com cauterização, ligadura do vaso acometido ou bandagem compressiva. A cicatrização deve ser por segunda intenção. Entre os tratamentos associados à remoção cirúrgica ressalta-se a administração de anfotericina B (RODRIGUES e LUVIZOTTO, 2000; BIAVA et al., 2007).

Cesconet al.(2008), relataram um caso de um equino de 12 anos que apresentava três áreas acometidas por $P$. insidiosum. Uma grande na região ventral do pescoço, pequenas massas dispersas na região da tábua do pescoço e outra massa pequena na região do flanco. $O$ animal foi submetido a exérese cirúrgica da massa. No pós cirúrgico optou-se tratar a ferida cirúrgica por segunda intenção com utilização de clorexidine $2 \%$ para a limpeza, aplicando pó cicatrizante a base de óxido de zindo e spray repelente. Após 30 dias da cirurgia o animal encontrava-se em recuperação satisfatória.

Os fármacos antifúngicos são pouco eficientes contra a pitiose. O ergosterol é o componente de membrana celular alvo da ação da maioria dos antifúngicos, mas a membrana do $P$. insidiosum não contém esse esteróide (SANTURIO et al, 2001).

Os antifúngicos já descritos em tratamentos contra a pitiose incluem: anfotericina B, itraconazol, fluconazole, cetoconazole, terbinafina e iodeto de 
Bromerschenkel, I. e figueiró, G.M. Pitiose em equinos. PUBVet, Londrina, V. 8, N. 22, Ed. 271, Art. 1807, Novembro, 2014.

potássio (MARTINS, 2010). Devido ao tratamento demorado (SANTURIO et al., 2001) e a nefrotoxidade desses fármacos é necessário o monitoramento constante das concentrações séricas de uréia e creatinina. A forte irritação causada por esses fármacos também podem causar flebite (NOBRE et al., 2002).

Coltroet al. (2011) relataram o tratamento com iodeto de potássio, após a excisão cirúrgica das lesões cutâneas causadas por $P$. insidiosum em um equino. Foi feita a administração de $24 \mathrm{~g}$ por dia, via oral na ração, uma vez ao dia durante três meses, além da limpeza diária do local da lesão. Após 75 dias o ferimento estava totalmente cicatrizado.

Uma alternativa para o tratamento de pitiose em membros de equinos é a administração de anfotericina $B$, por perfusão regional intravenosa associada à remoção cirúrgica, promovendo a cura com mínimas reações adversas (DÓRIA, 2009).

A imunoterapia foi utilizada com modificações e resultados variados ao longo dos anos 80 e 90 nas diferentes espécies (MILLER, 1981; SANTURIO et al., 2006). Atualmente a imunoterapia tem sido empregada utilizando-se culturas de fungo fenolizadas, expostas as ondas ultrassonicas, e as hifas são maceradas e liofinizadas (BIAVA et al., 2007). As taxas de cura com o uso da imunoterapia geralmente são calculadas com base em um número pequeno de animais, e geralmente o tratamento é combinado com o uso de outras terapias, tais como excisão cirúrgica e administração de agentes antimicrobianos (GAASTRA et al., 2010).

A ação da imunoterapia ainda é baseada em hipóteses, uma vez que ainda não há um completo conhecimento dos mecanismos envolvidos na infecção por $P$. insidiosum (SANTURIO et al., 2006). Miller (1981) e Mendoza, Mandy, Glass (2003), na realização de estudos histopatológicos, demonstraram que, com o uso do imunoterapico, as hifas do $P$. insidiosum são aparentemente destruídas pela população de células mononucleares. Henselet al. (2003), relataram um 
Bromerschenkel, I. e figueiró, G.M. Pitiose em equinos. PUBVet, Londrina, V. 8, N. 22, Ed. 271, Art. 1807, Novembro, 2014.

caso de cura da pitiose associada a imunoterapia, após o uso de duas doses de vacina anti- $P$. insidiosum. Através de biópsia observaram infiltração leve de macrófagos e plasmócitos. No GMS não foram vistas hifas. A partir desses trabalhos foi sugerido que o mecanismo da cura é predominantemente decorrente da resposta inume celular (MENDOZA e NEWTON, 2005). O desaparecimento da resposta eosinofílica, com o aumento acentuado de reação mononuclear observados após o tratamento com imunoterapico ajuda a dar suporte a essa hipótese (MILLER, 1981; HENSEL et al., 2003; MENDOZA, MANDY e GLASS, 2003).

A aplicação deve ser realizada a cada 14 dias, com injeções subcutânes na região do pescoço. No local onde é aplicado o imunoerapico é comum ocorrer reações como inchaço, dor, aumento da temperatura local ou formações de abcessos (MILLER, 1981; BIAVA et al., 2007).

A resposta à imunoterapia pode ser observada no prazo de 7 a 10 dias da primeira aplicação, com resolução progressiva de prurido, ressecamento da superfície da lesão, expulsão de kunkers, fibrose do granuloma e eventualmente epitelização completa (MILLER, 1981). Quanto mais recente e menor a lesão, menor será o número de aplicações do imunoterápico para a cura, mas vale ressaltar que alguns animais não respondem ao tratamento (SANTURIO et al., 2001).

Em um estudo utilizou-se 19 equinos para testar a eficácia de um imunológico em animais infectados naturalmente pelo $\mathrm{P}$. insidiosum. $\mathrm{O}$ mesmo se mostrou eficaz com um índice médio de cura de $63 \%$, resultante de um numero médio de 5,5 aplicações por animal. O mesmo estudo também demonstrou que não há diferença estatística entre lesões recentes, antigas ou recidivantes à resposta ao imunoterápico (MONTEIRO, 1999).

Santos et al. (2011), relataram um o caso de uma égua com pitiose facial e que devido a localização anatômica e dificuldade de transporte, optaram por tratar o animal exclusivamente com imunoterapia, utilizando um frasco de 
Bromerschenkel, I. e figueiró, G.M. Pitiose em equinos. PUBVet, Londrina, V. 8, N. 22, Ed. 271, Art. 1807, Novembro, 2014.

imunoterápico a cada 14 dias, com acompanhamento da evolução do caso. Foram aplicadas cinco doses do imunoterapico, e aos 70 dias de tratamento houve a regressão completa da lesão, permanecendo apenas uma cicatriz.

Tomichet al. (2010), realizaram um estudo avaliando o impacto econômico decorrente do controle da pitiose equina empregando-se o imunoterápico PITIUM-VAC ${ }^{\circledR}$, e os resultados indicam o potencial da adoção da estratégia de emprego do imunoterapico no controle da pitiose em equinos para gerar amplo impacto econômico positivo para o agronegócio do cavalo no Brasil.

A utilização de laser é feita após a remoção cirúrgica da massa lesionada, reduzindo assim o risco de recorrência, pois a fotoablação causa necrose térmica nos tecidos circundantes, podendo matar os organismos que estão infiltrados nesses tecidos. Sedrishel al. (1997), relataram o caso de dois equinos tratados com laser, onde os animais se recuperaram e não tiveram recidiva.

O tratamento tópico com DMSO associado à anfotericina $B$, após a excisão cirúrgica do tecido granulomatoso foi relatado por Dias et al. (2011). O tratamento consistiu em excisão cirúrgica da lesão, seguida de tratamento tópico, com limpeza da ferida cirúrgica com iodo povidine e aplicação de uma solução composta de $50 \mathrm{mg}$ de anfotericina $B, 10 \mathrm{ml}$ de água estéril e $10 \mathrm{ml}$ de DMSO. A lesão regrediu totalmente. Este tratamento mostrou-se economicamente viável, de baixo risco e eficaz.

Chaffin, Schumacher e Hooper (1992), relataram um caso de pitiose em um potro de cinco meses com lesões cutâneas no dorso e prepúcio, que foi tratado com excisão cirúrgica das feridas e iodeto de sódio administrado por via oral por duas semanas. Após três meses da cirurgia, todas as lesões estavam curadas.

Meireles et al. (2003), utilizaram a associação de exérese cirúrgica, iodeto de potássio intravenoso e aplicação tópica de sulfato de cobre em cinco cavalos 
BROMERSCHENKeL, I. e FIGUeIRÓ, G.M. Pitiose em equinos. PUBVet, Londrina, V. 8, N. 22, Ed. 271, Art. 1807, Novembro, 2014.

com diagnóstico de pitiose sem sucesso. Maciel et al. (2008), relatam que a aplicação tópica de sulfato de cobre irrita a lesão e dificulta a sua cicatrização.

Em bovinos, já foi relatado cura espontânea das lesões em animais afetados (SANTURIO et al., 1998; GABRIEL et al., 2008; GRECCO et al., 2009). Este fato foi atribuído, em parte, a resposta inflamatória/imune diferente que os bovinos em relação aos equinos, supostamente por suas lesões não apresentarem kunkers (GABRIEL et al, 2008).

Nos animais silvestres em que a doença já foi relatada, nenhum sobreviveu a doença, vindo a óbito entre um e 10 meses de manifestação da doença (GROOTERS, 2003; (CAMUS,GROOTERS e AQUILAR, 2004; WELLEHAN, et al., 2004; BUERGELT, POWE e WHITE, 2006; PESAVENTO et al, 2008).

\section{CONCLUSÃO}

Apesar de vários estudos sobre a pitiose, ainda são se chegou a um consenso sobre a sua patogenia e um perfeito entendimento sobre a resposta imunológica do hospedeiro ao $P$. insidiosum. De todos os tratamentos já relatados, o mais promissor é o uso da imunoterapia, que pode ser usada isolada ou em associação com outros tratamentos. Ainda são necessários mais estudos para que a patogenia e o mecanismo de resolução clínica da pitiose em equinos sejam melhor esclarecidos.

\section{REFERÊNCIAS}

BANDEIRA, A.M.P. et al. Pitiose equina no estado de Sergipe, Brasil. Ciênc. Vet, tróp., Recife$P E$, v.12, $\mathrm{n}^{\mathrm{S}} 1 / 2 / 3$, p. 46-54, 2009.

BIAVA, J.S. et al. Zicomicose em equinos - revisão. Rev. Acad., Curitiba, v.5, n. 3, p. 225$230,2007$.

BOSCO, S. M. G. et al. Human pythiosis, Brazil.EmergingInfectiousDiseases, Estados Unidos, v. 11, n. 5, p. 715-718, 2005. 
BUERGELT, C.; POWE, J.; WHITE, T. Abdominal pythiosis in a Bengal tiger (Pantheratigristigris). Journal of Zoo and Wildlife Medicine, EstadosUnidos, v. 37, n. 2, p. 186-189, 2006.

CAMUS, A. C.; GROOTERS, A. M.; AQUILAR, R. Granulomatous pneumonia caused by Pythiuminsidiosumin a central American jaguar, Pantheraonca. Journal of Diagnostic Investigation, Athens, v. 16, p. 567-571, 2004.

CESCON, G.T. et al. Tratamento cirúrgico de pitiose cutânea em um equino - relato de caso. Disponível em: http://www.sovergs.com.br/conbravet2008/anais/cd/resumos/r0702-2pdf acesso dia 15 de agosto de 2011.

CHAFFIN, M.K.; SCHUMACHER, J.; HOOPER, N. Multicentric cutaneous pythiosis in a foal.J. Am. Vet. Med. Assoc, v.201, n.2, p. 310-312, 1992.

CHAFFIN, M.K.; SCHUMACHER, J.; McMULLAN, W.C. Cutaneous pythiosis in the horse.Vet. Clin.North Am. Equine Pract.v.11, n.1, p. 91-103, 1995.

CHAIPRASERT, A. et al. PythiuminsidiosumThai isolates: molecular phylogenetic analysis. AsianBiomedicine, Tailândia, v. 3, n. 6, p. 623-633, 2009.

COLTRO, E. et al. Tratamento de pitiose equina utilizando iodeto de potássio - Relato de caso. Disponível em http://www.revista.ulbrajp.edu.br/ojs/index.php/ciencia/article/viewfile/25l/pdf . Acessado em 15 de agosto de 2011.

DALTO, A.G.C., et al. Pitiose intestinal em um equino no Rio Grande do Sul. Rev. Univ. Rural, v. 27, suplemento, p.131-133, 2007.

D'ULTRA VAZ, B.B.et al. Pitiose nasal em equino. Medicina Veterinária, Recife. v.3, n.4, p. 27-32, 2009.

DIAS, D.P.M. et al. Pitiose cutânea equina de localização atípica tratada topicamente com solução de anfotericina B e DMSO. Disponível em http://www.equalli.com.br/upload/textospdf/prf/809.pdf acessado dia 15 de agosto de 2011.

DÓRIA, R.G.S. et al. Relato do primeiro caso de transmissão direta de pitiose em equinos no estado do Mato Grosso. BrazilianJournalofEquine Medicine. n.28 p.26-29, 2010.

DÓRIA, R.G.S. Tratamento da pitiose em membros de equinos por meio de perfusão regional intravenosa com anfotericina B. 113f. Tese (Doutorado em Cirurgia Veterinária) - Faculdade de Ciências Agrarias e Veterinárias, Unesp, Câmpus de Jaboticabal, São Paulo, 2009.

FIORETTI, E.G.et al. Pitiose em equino no norte do paraná - relato de caso. XI Encontro Anual de Iniciação Científica, Maringa - PR, 2002.

FREY JUNIOR, F. et al. Pitiose equina na região Sul do Brasil. Revista Portuguesa de Ciências Veterinárias. v.102, p. 107-111, 2007.

GAASTRA, W. et al. Pythiuminsidiosum: an overview. Veterinary Microbiology, Holanda, v. 146 , n. 1-2, p. 1-16, 2010.

GABRIEL, A.L. et al. Surto de pitiose cutânea em bovinos.Pesq. Vet. Bras. v.28, n.12, p.583$587,2008$.

GRECCO, F.B. et al. Pitiose cutânea em bovinos na região Sul do Rio Grande do Sul. Pesq. Vet. Bras.v.29, n.11, p.938-942, 2009. 
GROOTERS, A. M. Pythiosis, lagenidiosis, and zygomycosis in small animals.The Veterinary Clinics of North America.Small Animal Practice, EstadosUnidos, v. 33, n. 4, p. 695-720, 2003.

GROOTERS, A.M.; GEE, M.K. Development of a nested polymerase chain reaction assay for the dectection and identification of Pythiuminsiosum.Journal of Veterinary Internal Medicine, v.16 n. 2 p. 147-152, 2002.

HEADLEY, S.A.; ARRUDA JUNIOR, H.N. Equine cutaneous pythiosis: a report of four cases. Ciência Rural, Santa Maria. v.34, n.1, p. 289-292, 2004.

HENSEL, P.; GREENE, C. E.; MEDLEAU, L. Immunotherapy for treatment of multicentric cutaneous pythiosis in a dog.Journal of the American Animal Hospital Association, EstadosUnidos, v. 223, n. 2, p. 215-218, 2003

KNOTTEMBELT, D.C.; PASCOE, R.R. Afecções e Disturbios do Cavalo. Barueri: Editora Manole, 1998, 432p.

LEAL, A.B.M. et al. Pitioseequine no Pantanal brasileiro: aspectos clínico-patológicos de casos típicos e atípicos. Pesquisa Veterinária Brasileira, v. 21, p.151-156, 2001.

LEAL, A.T. et al. Pitiose. Ciência Rural, Santa Maria, v.31. n.4, p. 735-743, 2001.

LUVIZARI, F.H.; LEHMKUHL, R.C.; SANTOS, I.W. Pitiose equina no estado do Paraná primeiro relato de caso. Archives of Veterinary Science, v.7, n.2, p.99-102, 2002.

MACIEL, I.C.F. et al. Pitiose fatal em equino tratato inicialmente para habronemose cutânea.Acta ScientiaeVeterinariae. v.36 n.3 p.293-297, 2008

MARQUES, S.A. et al. Pytiuminsidiosum: relato do primeiro caso de infecção humana do Brasil. Anais Brasileiros de Dermatologia. v.81 n.5 p.483-485, 2006.

MARTINS, T.B. Morfologia comparada da pitiose em cavalos, cães e bovinos. 106 f. Dissertação (Mestrado em Medicina Veterinária) - Universidade Federal de Santa Maria, Santa Maria, Rio Grande do Sul, 2010.

MEIRELES, M.C.A. et al. Cutaneous pythiosis in horses from Brazil. Mycoses, v. 36 n.3-4 p.139-142, 1993.

MENDOZA, L. et al. Serodiagnosis of humam and animal pythiosis using na enzymelikedimmunosorbent assay. Clinical and Diagnostic Laboratory Immunilogy, v.4, n.6, 1997.

MENDOZA, L.; ALFARO, A. A. Equine pythiosis in Costa Rica: report of 39 cases. Mycopathologia, Holanda, v. 94, p. 123-129, 1986.

MENDOZA, L.; HERNANDEZ, F.; AJELLO, L. Life cylcle of the human and animal oomycete pathogen Pythiuminsidiosum.J. Clin. Microbiol.v.31 n.11 p. 2967-2973, 1993.

MENDOZA, L.; KAUFMAN, L.; STANDARD, P.G. Immunodiffusion test for diagnosing and monitoring pythiosis in horses.Journal of Clinical Microbiology, v.23 n.5, p.813-816, 1986.

MENDOZA, L.; MANDY, W.; GLASS, R.An improved Pythiuminsidiosum-vaccine formulation with enhanced immunotherapeutic properties in horses and dogs with pythiosis.Vaccine, Holanda, v. 21, n. 21-22, p. 2797-2804, 2003

MENDOZA, L.; NEWTON, J. C. Immunology and immunotherapy of the infections caused by Pythiuminsidiosum. Medical Mycology, Inglaterra, v. 43, p. 477-486, 2005. 
MILLER R.I. Investigations into the biology of three 'phycomycotic' agents pathogenic for horses in Australia. Mycopathologia, v.81 n.1 p. 23-28, 1983.

MILLER; R. I. Treatment of equine phycomicosis by immunotherapy and surgery.AustralianVeterinaryJournal, Australia, v. 57, p. 377-392, 1981

MONTEIRO, A. B. Imunoterapia da pitiose equina: teste de eficácia de um imunobiológico e avaliação leucocitária em animais infectados naturalmente pelo Pythiuminsidiosum.1999. 52 p. Dissertação (Mestrado em Medicina Veterinária) - Universidade Federal de Santa Maria UFSM, Santa Maria, 1999

NOBRE, M.O. et al. Drogas antifúngicas para pequenos e grandes animais. Ciência Rural, v.32, p. 175-185, 2002.

PEDROSO, P.M.C. et al. Diagnóstico imuno-histoquímico de pitiose cutânea em equinos. Acta ScientiaeVeterinariae v. 37 n. 1 p. 49-52, 2009.

PEREIRA, D.B.; MEIRELES, M.A. Pitiose. In: ed, Santa Maria: Pallotti, 2007. p. 457-466.

Doenças de rumunantes e equídeos. $3^{a}$

PESAVENTO, P. A. et al. Cutaneous pythiosis in a nestling white-faced ibis. Veterinary Pathology, EstadosUnidos, v. 45, p. 538-541, 2008.

PURCELL, K.L. et al. Jejunal obstruction caused by a Pythiuminsidiosum granuloma in a mare.J. Am. Vet. Med. Assoc. v.205, n.2, p.337-339, 1994.

REIS JÚNIOR, J.L.; NOGUEIRA, R.H.G. Estudo anatomopatológico e imunoistoquímico da pitiose em equinos naturalmente infectados. Arquivo Brasileiro de Medicina Veterinária e Zootecnia. v.54, n.4, Belo horizonte, 2002. Disponível em: http://dx.doi.org/10.1590/S0102$\underline{09352002000400004}$

RODRIGUES, C.A.; LUVIZOTTO, M.C. Zicomicose e pitiose cutânea em equinos: diagnóstico e tratamento. Ver. Educ. Contin. CRMV-SP, v.3, fascículo 3, p.03-11, 2000.

SALLIS, E.S.V.; PEREIRA, D.I.B.; RAFFI, M.B. Pitiose cutânea em equinos: 14 casos. Ciência Rural, Santa Maria, v.33, n.5, p. 899-903, 2003.

SANTOS, C. E. P. et al. Eficácia da imunoterapia no tratamento de pitiose facial em equino. Acta ScientiaeVeterinariae. v.39, n. 1. 2011.

SANTURIO, J.M. et al. Teste de ELISA indireto para o diagnóstico sorológico de pitiose. Pesq. Vet. Bras. v.26, n.1, p. 47-50, 2006.

SANTURIO, J.M. et al. Tratamento imunoterapico da pitiose equina. Comunicado Técnico Embrapa Gado de Corte, 2001.2 Disponível em http://www.cnpgc.embrapa.br/publicaçoes/cot/COT67.html acessado dia 14 de agosto de 2011.

SANTURIO, M.J. et al. Cutaneous Pythiosisinsidiosi in calves from the Pantanal region of Brazil. Mycopathologia, v.141, n. 3, p. 123-125, 1998.

SANTURIO, M.J. et al. Pitiose: uma micose emergente. Acta ScientiaeVeterinariae v.34 n.1 p. 1-14, 2006.

SCHURKO, A. M. et al. A molecular phylogeny of Pythiuminsidiosum.Mycological Research, Inglaterra, v. 107, p. 537-544, 2003 
SEDRISH, S.A. et al. Adjunctive use of a neodymium: yttrium-aluminum garnet laser for treatment of pythiosis granulomas in two horses. J. Am. Vet. Assoc. v.211 n. 4 p.464-465, 1997.

SUPABANDHU, $\mathrm{J}$. et al. Isolation and identification of the human pathogen Pythiuminsidiosumfrom environmental samples collected in Thai agricultural areas. Medical Mycology, Inglaterra, p.1-12, 2008.

TABOSA, I.M. et al. Outbreaks of pythiosis in two flocks of sheep in northeastern Brazil.Vet. Pathol.v.41, n. 4, p. 412-415, 2004.

TOMICH, T. E. et al. Impacto economico decorrente do controle da pitioseequine empregandose o imunoterápico PITIUM-VAC. $5^{\circ}$ simpósio sobre recursos naturais e socioeconômicos do pantanal. Corumbá- MS, 2010.

VANITTANAKOM, N. etal.Identification of emergins human-pathogenic Pythiuminsidiosum by serological and molecular assay-based methods. Journal of Clinical Microbiology, v.42, n.9, 2004.

VICARIVENTO, N.B. et al. Pitiose: Uma micose emergente nos humanos. Revista Científica Eletrônica de Medicina Veterinária. Ano VI, no 10, 2008.

WELLEHAN, J. F. X. et al. Pythiosis in a dromedary camel (Camelusdromedarius). Journal of Zoo and Wildlife Medicine, EstadosUnidos, v. 35, n. 4, p 564-568, 2004 